\title{
Intra-arterial migration of a fractured endoscopic needle
}

A 53-year-old man with chronic pancreatitis presented with abdominal pain and sepsis. Imaging revealed a liver abscess secondary to distal biliary obstruction. Following drainage of his abscess, the patient underwent endoscopic retrograde cholangiopancreatography (ERCP) with placement of a fully covered metal biliary stent across a $2-\mathrm{cm}$ suspicious shouldered and irregular low common bile duct stricture. A pancreatic head malignancy was suspected at ERCP and on computed tomography (CT) imaging. The regional specialist hepatobiliary multidisciplinary team (MDT) recommended endoscopic ultrasound with fine needle aspiration (EUS-FNA).

EUS-FNA was difficult because of the changes of severe chronic calcific pancreatitis, duodenal stenosis, increased pancreatic head vascularity, and metal stent artefact. Five needle passes were made with a 22-gauge needle (Boston Scientific, Marlborough, Massachusetts, USA) using standard technique. Cytology was consistent with pancreatitis, with no evidence of malignancy.

A routine chest radiograph 6 months later revealed a new linear density in the heart ( $>$ Fig.1). The interim abdominal CT imaging was re-reviewed ( $\mathbf{F i g . 2}$ ). Although not recognized at the time, owing to the highly calcified pancreas, it became clear that a fractured EUS-needle tip had migrated from the duodenal wall into the epigastrium ( $\triangleright$ Fig.3), then through the diaphragm and into the left ventricle. On a subsequent chest radiograph, the needle had disappeared and a further $\mathrm{CT}$ scan revealed that it had migrated to the aortic bifurcation ( Fig.4a).

The needle was retrieved endovascularly via bilateral common femoral artery access. It was first snared from above with a protective occlusion balloon placed below in the left iliac artery ( $\mathbf{F i g . 4 b ) . ~ T h e ~ b a l l o o n ~ w a s ~ d e f l a t e d , ~}$ the needle was snared from below and was then removed through the left groin
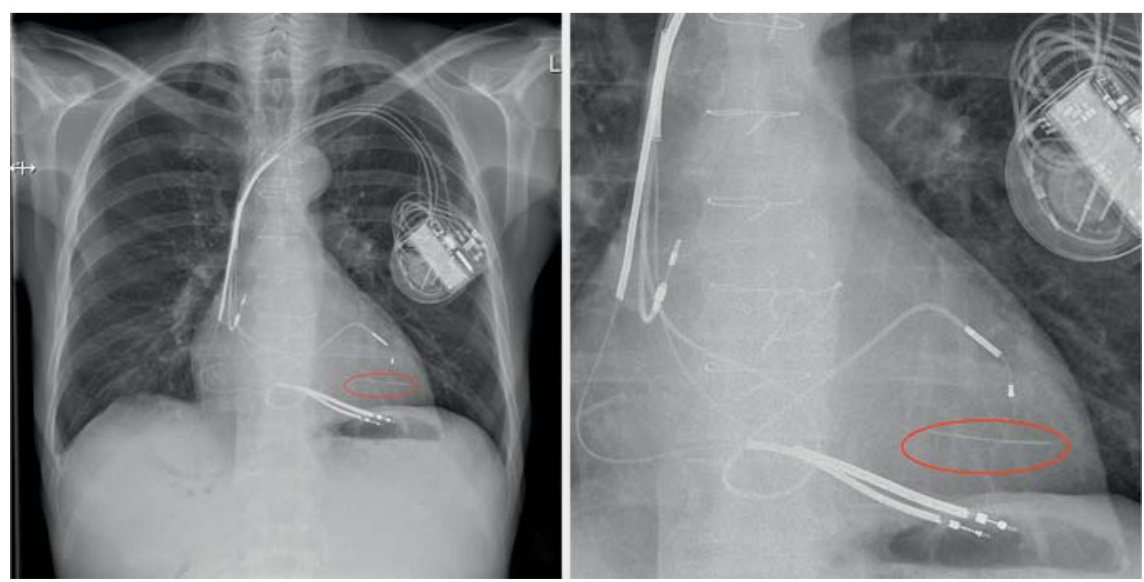

- Fig. 1 Chest radiograph showing a needle within the left ventricle (linear density within the red ellipse).

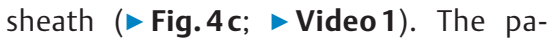
tient made an uneventful recovery after the procedure.

Endoscopic needle fracture has been previously described in the upper gastrointestinal tract $[1,2]$ and in a bronchoscopy setting [3]. Fractured metal sharps such as orthopedic fixation wires have been known to migrate into the arterial circulation, including into the heart [4].
This is the first known case of an endoscopic needle migrating intra-arterially.

Endoscopy_UCTN_Code_CPL_1AJ_2AZ

Competing interests

None 


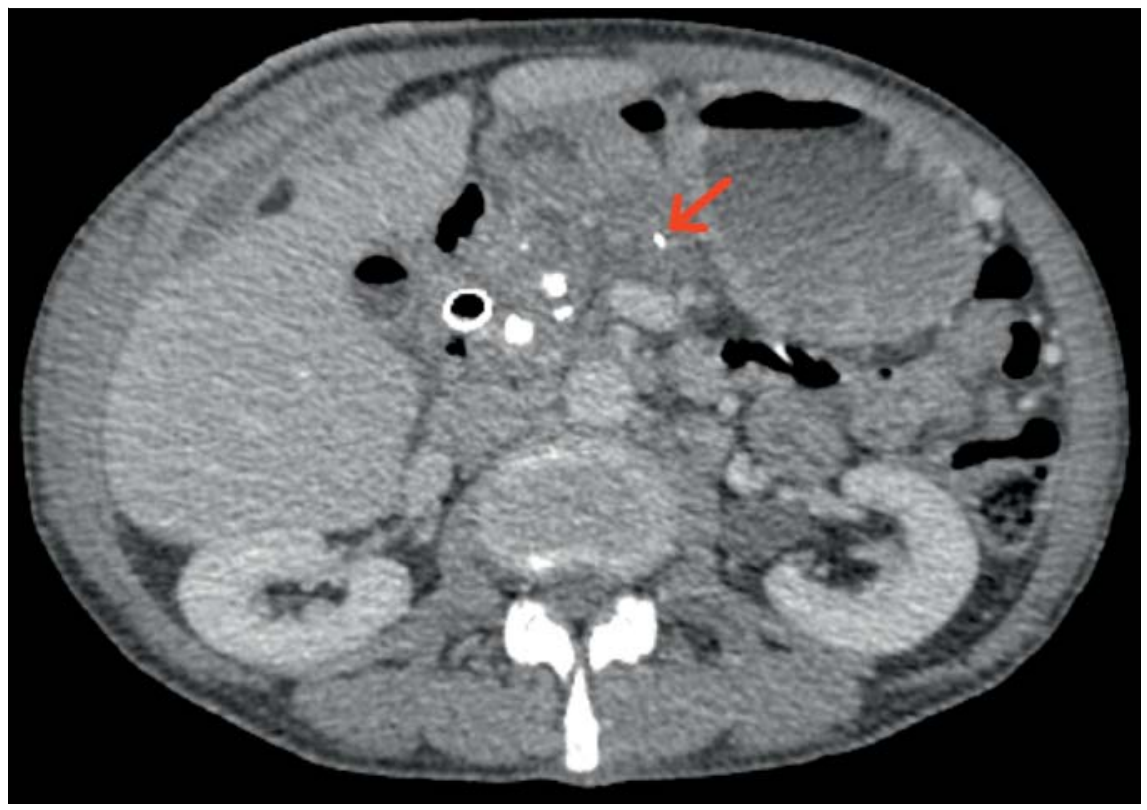

The Authors

Edward Lake', Joanne Puleston², Finn Farquharson ${ }^{1}$

1 Department of Radiology, Central Manchester University Hospitals NHS Foundation Trust, Manchester, UK

2 Department of Gastroenterology, Central Manchester University Hospitals NHS Foundation Trust, Manchester, UK

Corresponding author

Edward Lake, MD

Department of Radiology, Manchester

Royal Infirmary, Grafton Street, Manchester, M13 9WL, UK

edwardlake@yahoo.com

- Fig. 2 Axial computed tomography (CT) scan showing the needle (red arrow) that was not identified originally among the pancreatic calcifications.
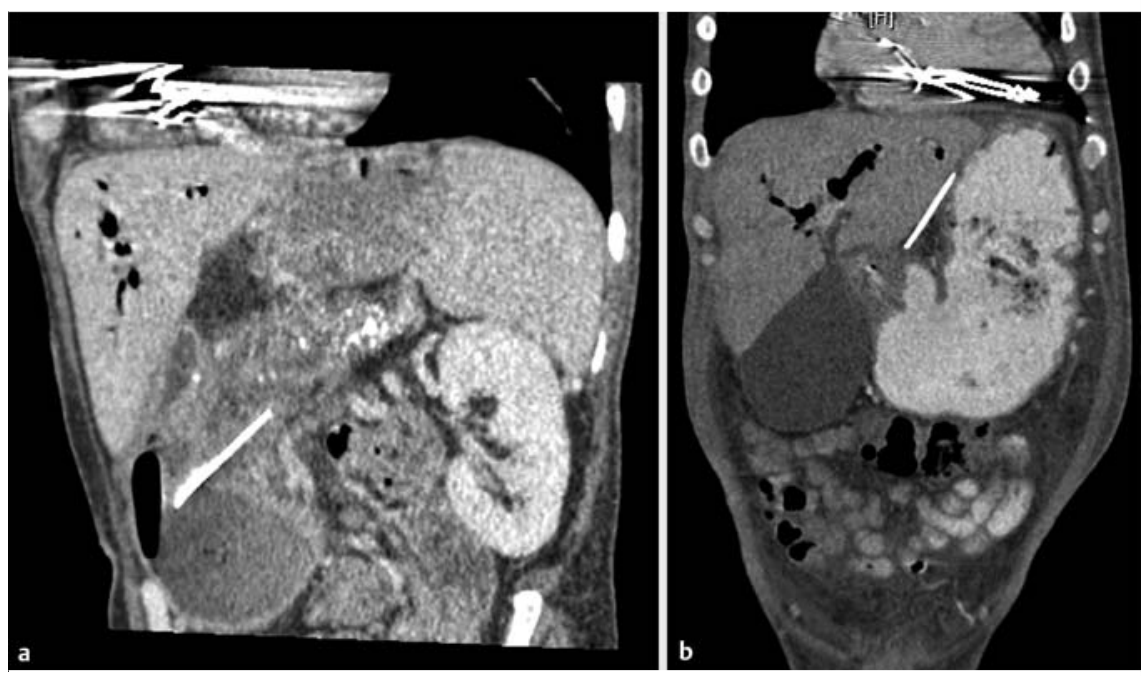

- Fig. 3 Obliquely reformatted computed tomography (CT) images showing: a the needle extending through the duodenal wall; $\mathbf{b}$ the needle having moved to the epigastrium. 

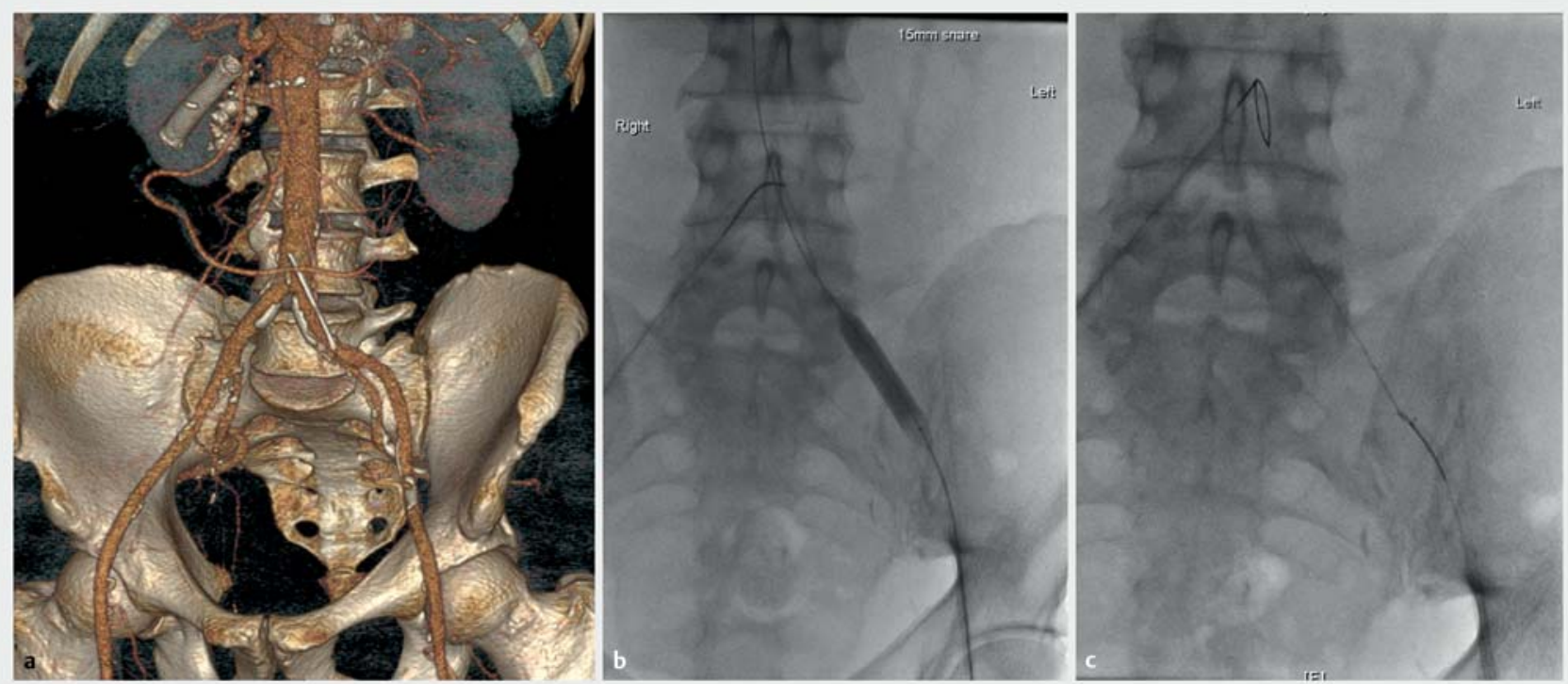

- Fig. 4 Further imaging shortly before and during removal of the needle. a A volume-rendered computed tomography (CT) angiogram showing the needle at the aortic bifurcation. $\mathbf{b}$ The needle was snared from above with balloon occlusion below. $\mathbf{c}$ The needle was snared from below and was removed through a sheath.

\section{References}

[1] Rimbaș M, Attili F, Andrade Zurita S et al. Fractured needle during endoscopic ultrasound-guided fine-needle aspiration of a pancreatic head mass. Endoscopy 2015; 47 (Suppl. 01): E432

[2] DeWitt J, Sherman S, Lillemoe KD. Fracture of an EUS-guided FNA needle during an attempted rendezvous for an inaccessible pancreatic duct. Gastrointest Endosc 2011; 73: $171-173$
[3] Özgül MA, Çetinkaya E, Tutar $\mathrm{N}$ et al. An unusual complication of endobronchial ultrasound-guided transbronchial needle aspiration (EBUS-TBNA): the needle breakage. Ann Thorac Cardiovasc Surg 2014; 20 Suppl: 567-569

[4] Leonardi F, Rivera F. Intravascular migration of a fractured cerclage wire into the left heart. Orthopedics 2014; 37: e932 - e935

\section{Bibliography}

DOI http://dx.doi.org/10.1055/s-0042-123704 Endoscopy 2017; 49: E70-E72

(c) Georg Thieme Verlag KG

Stuttgart · New York

ISSN 0013-726X 